\title{
Análise de Obras Cinematográficas para Compreender as Concepçóes de Professores sobre o Aluno com DeficiênCia ${ }^{1}$ ANALYSIS OF CINEMATOGRAPHIC WORKS TO UNDERSTAND TEACHERS'CONCEPTIONS of STUDENTS WITH DISABILITIES
}

\author{
Mateus Henrique do AMARAL ${ }^{2}$ \\ Maria Inês Bacellar MONTEIRO3
}

RESUMO: o movimento de inclusão dos alunos com deficiência no ensino básico apresenta dificuldades de efetivação, principalmente pelo forte bloqueio dos professores ante esses discentes em sala de aula, fato que advém, sobretudo, das concepções negativas de deficiência que mediam as relaçóes de ensino e interferem no processo de inclusão. Essas noçóes são construídas historicamente e reforçadas pelos grandes meios de comunicaçáo social. Partindo da ideia de que hoje o cinema se configura como um dos principais disseminadores de comportamentos, este estudo objetiva refletir as relaçóes entre as representações dos sujeitos com deficiência e as concepções que mediam a interação dos professores com seus alunos. Para tanto, levantamos filmes recentes que têm a deficiência como temática, organizamos os resultados em gráficos com variáveis quantitativas e relacionamos esses dados com estudos sobre cinema e deficiência e consideraçôes da perspectiva histórico-cultural, que permitem fundamentar que as relaçôes sociais influenciam na constituiçâo pessoal dos indivíduos. Encontramos 250 filmes e verificamos que a representação atual mais comum é pela dramatização pessoal. A análise das obras cinematográficas permitiu identificar que as concepçóes de limitação dos professores sobre seus alunos com deficiência fazem parte de um imaginário social que vem sendo retratado e reafirmado, também, pelo cinema. É possível propor discussôes com os docentes sobre o modo como a pessoa com deficiência é retratada: apenas por sua incapacidade e náo por suas qualidades. Essa ideia socialmente estigmatizada em geral faz com que ele limite esses alunos, sem explorar seus potenciais.

PALAVRAS-CHAVE: Educação Especial. Cinema. Deficiência.

\begin{abstract}
The movement to include students with disabilities in basic education faces difficulties of implementation, especially due to the block teachers have with these learners in their classroom, fact that derives especially from the negative conceptions of disabilities that mediate education relations and interfere with the inclusion process. These notions are historically constructed and strengthened by major social communication media. Starting from the idea that today movies are configured as one of the main behavior disseminators, this study aims to reflect on the relations between the representations of people with disabilities and the conceptions that mediate the interactions between teachers and their students. Thus, recent movies focused on the theme disabilities were collected, the results were organized in graphics with quantitative variables and these data were related to studies about movies and disabilities and considerations of the historical and cultural perspective, which allow to argue that social relations influence the personal constitution of the individuals. We found 250 films and verified that the most common current representation is of personal dramatization. The analysis of the cinematographic works allowed to identify that the conceptions of limitation teachers have about their students with disabilities are part of a social imagery that has been portrayed and reiterated, also, by movies. It is possible to propose discussions with teachers on how the person with disability is portrayed: only for their disability and not for their qualities. This socially stigmatised idea, in general, prevents teachers from exploring their potentials.
\end{abstract}

KEYWORDS: Special Education. Movies. Disability.

1 Apoio Financeiro: FAPESP, processo n. 2013/08991-6. Bolsa PIBIC/CNPq, processo CONSEPE n. 3314. http://dx.doi.org/10.1590/S1413-65382216000400004

2 Universidade Metodista de Piracicaba. Faculdade de Ciências Humanas. Piracicaba, SP, Brasil. amaralmateush@gmail.com 3 Docente do Programa de Pós Graduação em Educação, Universidade Metodista de Piracicaba. Faculdade de Ciências Humanas. Piracicaba, SP, Brasil. monteirobim@gmail.com 


\section{INTRODUÇÁo}

A partir da Declaração de Salamanca (BRASIL, 1994), documento assinado em 1994 que trata de princípios, políticas e práticas na área de necessidades educativas especiais (NEE), houve um crescente movimento de inclusão dos alunos com deficiência nas instituições escolares de diversos países.

No Brasil, na concretização desse movimento, primeiro foram implementadas diretrizes nacionais específicas e, aos poucos, os alunos com necessidades educativas especiais foram sendo inseridos nos ambientes escolares. Somente depois se passou a pensar em um dos pontos mais importantes dessa ação: a formação de profissionais para atuar com esses discentes nas escolas, a fim de criar condições de interação nesses espaços e, acima de tudo, garantir-lhes acesso ao conhecimento científico.

Em um estudo acerca da prática docente diante do aluno diagnosticado com deficiência, Monteiro, Freitas e Camargo (2014) observam que atualmente há um forte bloqueio dos professores ante este aluno em sala de aula, o que influencia no relacionamento interpessoal e no processo de ensino, atribuindo a culpa ao discente com deficiência pelos insucessos acadêmicos e impossibilitando que o trabalho pedagógico efetive-se.

Nos últimos anos, uma das maiores preocupaçóes observadas quando nos debruçamos sobre a leitura de estudos acerca da inclusáo dos alunos com deficiência nos ambientes escolares é a proposta de reflexão sobre o modo como eles são recebidos nesses ambientes e de que forma os profissionais ali presentes atuam com esses sujeitos, quer dizer, há uma grande preocupação em identificar que olhar é atribuído a esses alunos nos contextos educacionais inclusivos.

Tendo como base essa preocupação, Silveira, Enumo e Rosa (2012) realizaram um levantamento bibliográfico de estudos divulgados entre os anos 2000 e 2010 que trabalham com a concepção de professores sobre a inclusão escolar e as interaçóes em ambiente inclusivo. As autoras analisaram 29 artigos sobre a questão e notaram que as principais discussóes apresentadas apontam para os seguintes itens:
a) necessidade de políticas para a potencialização do enfrentamento e práticas educativas (12);
b) necessidade de formação de professores (11); c) comportamentos/ concepçóes de professores podem afetar o processo de [inclusão] (nove); d) resultados positivos em comportamento e concepçóes, a partir de intervençóes (cinco); e) importância da aceitação para promoção de ambiente inclusivo (cinco); f) enfrentamentos verificados (cinco); g) necessidade de trabalho pedagógico e de equipe que não enfatize a deficiência (quatro); h) problemas na efetivação dos princípios inclusivos (três); i) comportamento de alunos influenciado pelas concepçôes/percep- çôes (três) (SILVEIRA; ENUMO; ROSA, 2012, p.701).

De um modo geral, observamos um forte empenho na área no sentido de delinear caminhos para uma atuação efetiva dos profissionais da educação, principalmente dos professores, no que concerne ao ensino das pessoas com deficiência. Isso significa dizer que o problema já não se concentra tanto na inserção desses alunos nos espaços educativos, mas, sim, em pensar de que forma o conhecimento estará acessível a eles nesses espaços. 
Silveira, Enumo e Rosa (2012) perceberam que os estudos analisados normalmente relatam que as concepçóes de deficiência de profissionais da educação e de outros alunos estão ligadas à ideia de que são as características individuais que causam limitação. Destacam também que um dos pontos mais fortemente discutidos nos artigos é a necessidade de capacitação de professores e a reflexão de como o comportamento e as concepçóes desses docentes podem afetar o processo de inclusão.

As pesquisadoras acima apontam que a imagem do aluno limitado é uma concepção frequente entre os docentes, o que também pode ser notado no estudo desenvolvido por Monteiro, Freitas e Camargo (2014).

Essas concepções estão enraizadas não apenas na prática dos professores em sala de aula, como também refletem uma noção construída historicamente e que faz parte de todo um imaginário social, que entende a deficiência como algo puramente biológico e limitante.

Segundo Vigotski (1989), a deficiência não é determinada apenas biologicamente, fisicamente, mas, sim, construída nas relaçóes sociais e no grupo social ao qual o indivíduo com deficiência pertence. $\mathrm{O}$ enfoque dos estudos do autor não separa os indivíduos da situação cultural em que se desenvolvem.

A escolha de obras cinematográficas como objeto de análise e discussão, nesse texto, advém da compreensáo de que o cinema atua como reprodutor e produtor das relaçóes sociais, sentimentos pessoais e, acima de tudo, pela sensação de realidade mediada pelas imagens.

A linguagem cinematográfica, segundo Martin (1990), tem como base a imagem, que se coloca como a principal matéria-prima fílmica, que elenca, como destaca o autor, elementos como o movimento e o som.

A imagem fílmica suscita [...] no espectador, um sentimento de realidade bastante forte, em certos casos, para induzir à crença na existência objetiva do que aparece na tela. Essa crença, essa adesão, vai das reaçóes mais elementares, nos espectadores virgens ou pouco evoluídos, cinematograficamente [...] aos fenômenos bem conhecidos de participação (os espectadores que advertem a heroína dos perigos que a ameaçam) e de identificação com os personagens. (MARTIN, 1990, p.22, grifo do autor).

O que distingue, portanto, o filme, a linguagem cinematográfica, de outros meios de representação é o seu princípio básico, a reprodução fotográfica da realidade. Vale considerar que, juntamente com esse aspecto, essa linguagem também pode incluir outros princípios de interação verbal, como as linguagens escrita e oral.

Quanto às possibilidades dessa linguagem, Ferreira (2009), em um estudo sobre a importância da leitura cinematográfica para a formação do educador, coloca que o cinema é um grande meio de comunicação social, que influencia e dita formas de agir e pensar. Em acréscimo a este pensamento, acreditamos que a linguagem cinematográfica também intervém diretamente nas relaçóes sociais estabelecidas e, por isso, configura-se como uma das principais disseminadoras de comportamentos e representaçóes culturais. 
De acordo com Rizzo Junior (2011), hoje, o audiovisual atingiu grande importância social, já que por meio dessa forma de interação é que as pessoas comumente têm acesso ao entretenimento, à política e a outras informações e conhecimentos de mundo.

A partir da análise de filmes com temáticas relacionadas à deficiência, o presente artigo se propóe a refletir sobre possíveis relaçóes entre as representaçóes sociais das pessoas com deficiência e as concepçóes que mediam a interação de professores com seus alunos.

A análise das obras cinematográficas foi realizada a partir de levantamento de títulos de filmes produzidos entre 1994 e 2014 e posterior discussão de variáveis sistematizadas em gráficos, que foram quantificadas de acordo com o tipo de deficiência focalizada nos filmes, o ano de produção, o gênero e o país de origem.

Fundamentamo-nos em estudos que abordam as relaçóes do cinema com a deficiência, como os textos de Suplino (2010) e Albuquerque (2008), e na perspectiva histórico-cultural, especificamente nos estudos de Vigotski (1989), como forma de embasar as ideias sobre as influências das relaçóes sociais na constituição pessoal.

\section{Método}

O levantamento das obras fílmicas foi realizado a partir de consultas na rede social de filmes Filmow ${ }^{4}$, no banco de dados de obras cinematográficas $\mathrm{IMDb}^{5}$, no site de buscas Google $^{6}$, na página online oficial de algumas ediçóes do Festival Internacional de Filmes sobre Deficiência Assim Vivemos ${ }^{7}$, no banco de dados de estudos acadêmicos Google Acadêmico ${ }^{8}$ e na biblioteca de produçóes acadêmicas SciELO9.

Encontramos na rede social Filmow seis pastas digitais com diferentes seleçóes de filmes sobre deficiência: a primeira é intitulada Filmes sobre Deficiência Intelectual e contém trinta e nove títulos; a segunda é intitulada Filmes sobre Deficiência, Limites e Superação e possui dezoito itens; a terceira é intitulada Filmes sobre Deficiência Física e contém noventa itens; a quarta, com o título Filmes sobre Deficiência Visual, possui cinquenta e dois itens; a quinta, Filmes sobre Deficiência Física, contém vinte itens; e, por fim, a última pasta digital é intitulada Filmes sobre Deficiência Auditiva/Visual/Cognitiva e possui trinta e cinco itens.

Quanto ao banco de dados online IMDb, não encontramos pastas digitais específicas, apenas alguns títulos avulsos de obras pelo uso dos termos deficiency e deficiência na barra de pesquisa do site.

Por meio de pesquisas feitas no site de buscas Google, utilizando os termos filmes sobre deficiência, foram encontradas as seguintes páginas online e arquivos em PDF com listas sobre

\footnotetext{
${ }^{4}$ http://filmow.com

${ }^{5}$ http://www.imdb.com

${ }^{6}$ https://www.google.com

${ }^{7}$ http://www.assimvivemos.com.br

${ }^{8}$ https://scholar.google.com.br

${ }^{9}$ http://www.scielo.org/php/index.php
} 
filmes que abordam a deficiência: CSJ Online - arquivo em PDF ${ }^{10}$; Portal Filmes Educativos ${ }^{11}$, que contém diferentes seçôes de títulos de filmes que têm a deficiência como temática; lista feita por uma página na rede social Facebook, intitulada Psicopedagogia ${ }^{12}$; uma lista feita pelo blog Aprendizagem e desenvolvimento: ressignificando saberes e práticas na inclusão ${ }^{13}$; uma lista feita pelo site Pedagogia ao pé da letra ${ }^{14}$; uma lista feita pelo Portal Inclusivo do governo do estado do Ceará ${ }^{15}$; uma lista elaborada pelo Programa TEC NEP ${ }^{16}$ sobre filmes com temas abrangendo algum tipo de deficiência; e, por fim, uma lista feita pelo blog Sala de recursos e autismo ${ }^{17}$.

Já no site das ediçóes do Festival Internacional de filmes sobre deficiência Assim Vivemos, foi possível encontrar títulos de obras cinematográficas exibidas em alguns anos do festival. Essas obras estão organizadas nessas páginas online em diferentes seçóes, cada qual correspondendo a uma edição do festival. Além dos títulos dos filmes, é possível encontrar também informações pertinentes sobre essas obras, como o ano de produção, a direção, a sinopse e o país de origem.

Por fim, na SciELO e no Google Acadêmico, encontramos um artigo intitulado Comunicação e inclusão social: análise das contribuiçóes do cinema para o processo de inclusão social, produzido por Suplino (2010), uma dissertação intitulada $A$ pessoa com deficiência $e$ suas representaçóes no cinema brasileiro, produzida por Albuquerque (2008), e um trabalho de conclusão de curso intitulado Cinema e deficiência: Imagens da realidade e da arte, produzido por Katsuragi (2009), que fazem a análise de alguns filmes. A partir desses estudos, foi possível ampliar o levantamento dos títulos.

Após encontrar esses títulos em sites, listas e estudos acadêmicos, analisamos um a um, a fim de selecionar apenas aqueles com data de lançamento a partir de 1994, recorte feito em 2014, ano de início da pesquisa, para cobrir um período recente de produçóes cinematográficas sobre o assunto, de modo a compreender as ideias que permeiam as obras mais atuais.

Com a conclusão do levantamento, pesquisamos informações sobre cada título e separamos apenas os que tiveram lançamento datado entre 1994 e 2014. Posteriormente, organizamos esses dados em uma planilha do Excel, dividindo-os por abas correspondentes aos tipos de deficiência focalizados nas obras, elencando o título, ano de produção, direção, gênero e país de origem, e elaboramos gráficos com o intuito de tornar mais visíveis os dados quantitativos obtidos.

\section{Resultados e discussáo}

Os resultados obtidos na análise das obras cinematográficas permitiram relacionar as representaçóes do sujeito com deficiência no cinema e as concepçóes que mediam as interações de professores com seus alunos. Além disso, pautados nos pressupostos da perspectiva histórico-cultural, refletimos como as relações sociais influenciam na constituição pessoal.

\footnotetext{
${ }^{10}$ http://csjonline.web.br.com/PDF/Filmes_sobre_surdez.pdf.

${ }^{11} \mathrm{http}: / /$ www.filmeseducativos.com

${ }^{12}$ https://www.facebook.com/psicopedagogia.trocandoideias/posts/260942470707092?fref=nf

${ }^{13}$ http://eeaap47nb.blogspot.com.br/p/filmes-interessantes.html

${ }^{14} \mathrm{http}: / /$ pedagogiaaopedaletra.com/sugestoes-de-filmes-sobre-educacao-especial

${ }^{15} \mathrm{http}: / /$ www.portalinclusivo.ce.gov.br/index.php/bibliotecavirtual/filme.

${ }^{16} \mathrm{http}: / /$ portal.mec.gov.br/index.php?option=com_content\&view=article\&id=12779:programa-tec-nep\&catid=190:setec.

${ }^{17} \mathrm{http}: / /$ saladerecursoseautismo.blogspot.com.br/p/dicas-de-filmes-autismo.html.
} 
No total foram encontradas 250 obras produzidas entre 1994 e 2014 que têm a deficiência como temática.

A classificação por tipo de deficiência focalizada nessas obras mostra que trinta e seis são sobre o autismo, setenta e um são sobre deficiência auditiva, quarenta e três sobre deficiência física, trinta e quatro têm como temática principal a deficiência intelectual, quarenta e quatro trazem como principal tema a deficiência visual e vinte e duas abordam a Síndrome de Down.

O Gráfico 1 sistematiza essas informaçóes apresentando o número de obras cinematográficas por deficiência focalizada e a porcentagem correspondente a cada uma, a partir do total de títulos de filmes que integram nosso levantamento.

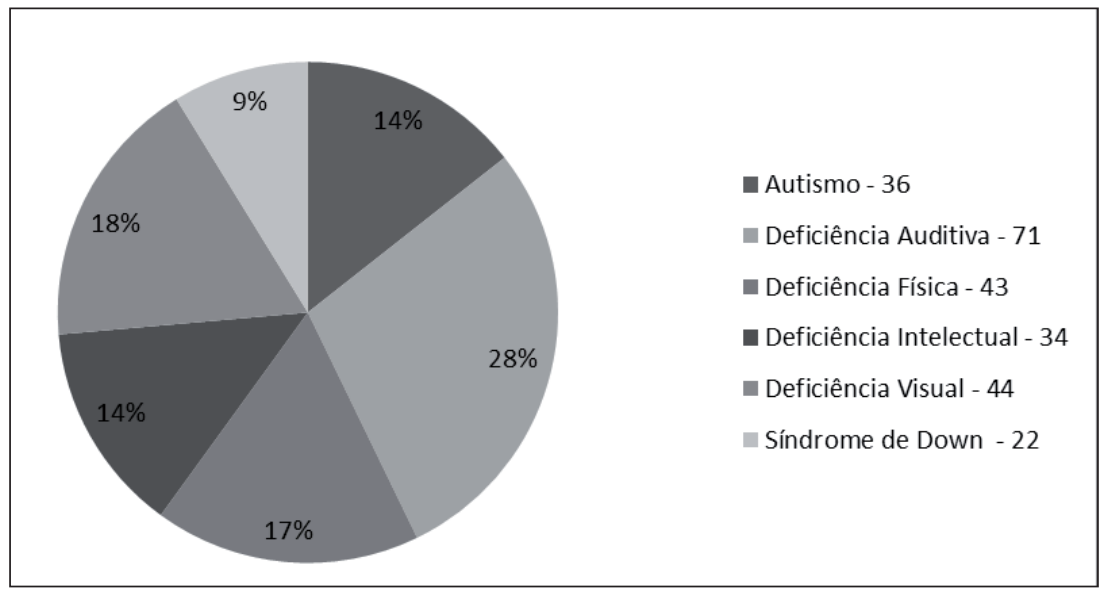

Gráfico 1 - Porcentagem dos títulos por tipo de deficiência focalizado Fonte: elaboração própria.

Há uma considerável predominância de títulos sobre a deficiência auditiva (28\%). Uma possível explicação desse fato pode estar no movimento da comunidade surda, que lutou e garantiu alguns direitos que possibilitam uma maior visibilidade, como, por exemplo, a obrigatoriedade da disciplina de Língua Brasileira de Sinais (LIBRAS) em cursos de formação inicial de professores e de Fonoaudiologia.

Para além desse considerável predomínio de obras com sujeitos e personagens com deficiência auditiva, o número de filmes encontrados por deficiência focalizada se encontra distribuído com poucas diferenças entre os outros tipos, com exceção da Síndrome de Down, que corresponde apenas a $9 \%$ das obras encontradas.

Ao considerar-se o número de produções por década, foram encontrados noventa e dois títulos com o lançamento entre os anos de 1994 e 2000, cento e vinte e nove lançados entre os anos 2001 e 2010 e vinte e nove com estreia a partir de 2011.

Essas informaçóes podem ser observadas no Gráfico 2, que apresenta a porcentagem de títulos por data de lançamento em cada uma das décadas. 


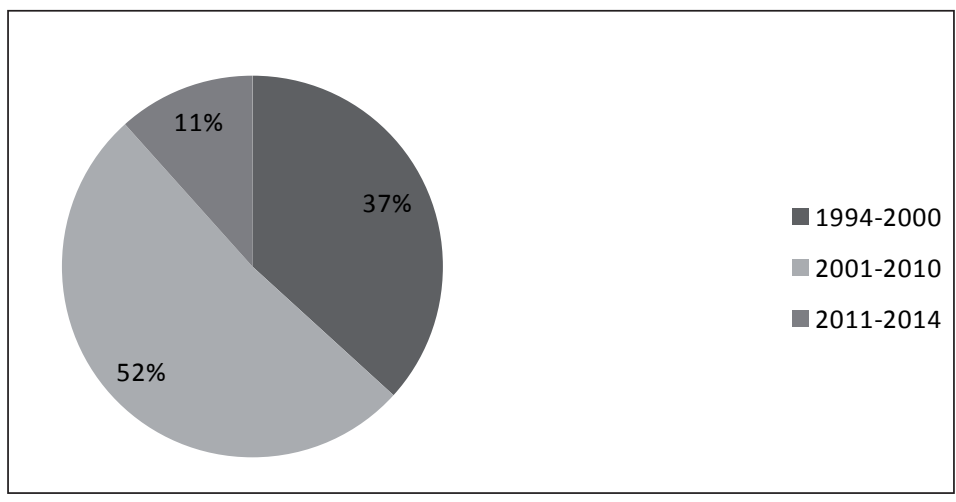

Gráfico 2 - Porcentagem de produções por década de lançamento Fonte: elaboração própria.

As obras cinematográficas produzidas na primeira década do século atual correspondem a mais da metade do total de títulos encontrados em nosso levantamento (52\%) e entre as outras duas décadas, existe uma grande diferença entre o número de filmes encontrados da década de noventa $(37 \%)$ e da segunda década do século vinte e um (11\%).

Consideramos que esses dados refletem dois fatores: o primeiro é o número de anos que cada década abrange no levantamento, já que a década de 2000 é a única com dez anos e a década de 1990 aparece com três anos a mais que a segunda década de 2000, e o segundo fator é a dificuldade de encontrar títulos recentes sobre a temática, devido ao número escasso dessas produçóes nas listas e pastas com obras sobre deficiência.

Uma grande parcela dos filmes mais atuais presentes no levantamento são obras que participaram do Festival Internacional de Filmes sobre deficiência Assim Vivemos, que tem uma atuaçáo pertinente no sentido de propor debates e reflexôes sobre a temática por meio dessas produçôes.

É importante que esses fatores acima sejam considerados na análise desses dados. No entanto, mesmo não tendo uma visão mais precisa do número de títulos por décadas, acreditamos que essa informação é pertinente, pois sugere a possível influência dos parâmetros e políticas em inclusão escolar e social, elaborados a partir da Declaração de Salamanca, assinada em 1994, na crescente produção de filmes sobre a temática nos anos posteriores.

Um dos dados mais importantes para a reflexão sobre as características das obras é o gênero fílmico que normalmente perpassa os assuntos abordados nessas produçôes, já que eles podem revelar o modo que determinada temática é entendida e representada socialmente.

Identificamos que o drama é o gênero comumente difundido nos filmes, correspondendo a cento e quatorze títulos dos duzentos e cinquenta encontrados. 


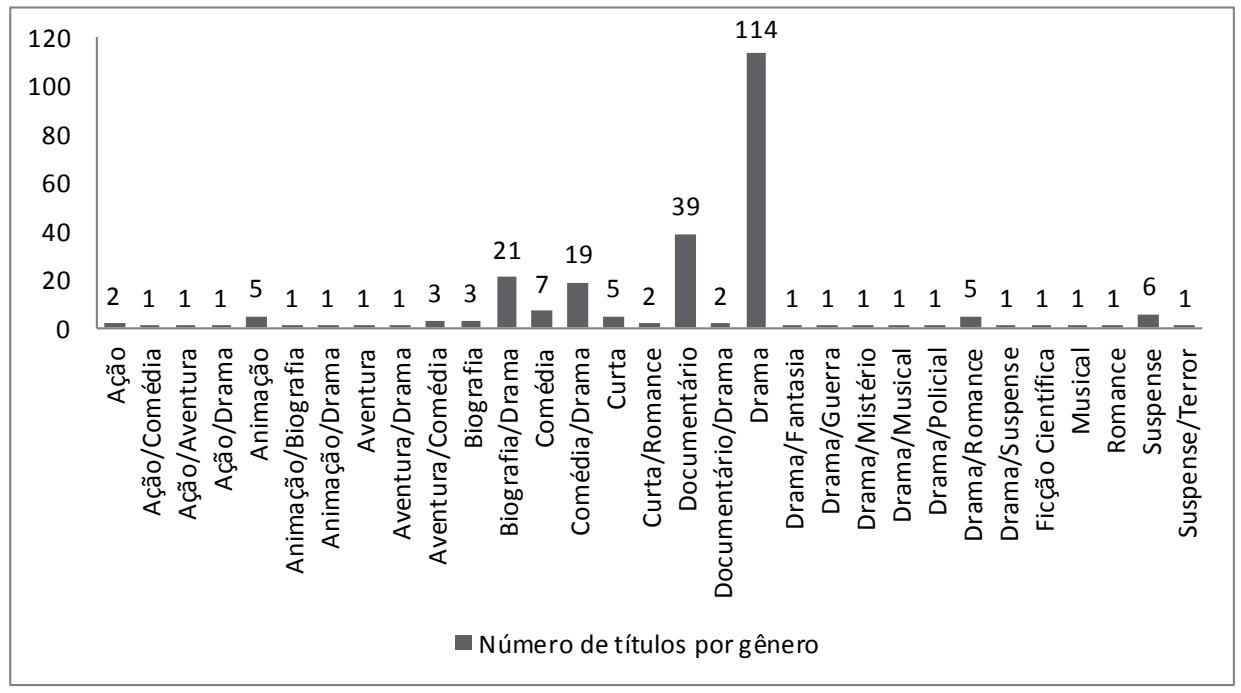

Gráfico 3 - Número de títulos por gênero fílmico

Fonte: elaboração própria.

O gráfico acima traz o número dos títulos encontrados por gênero fílmico. Exceto o drama (114), os gêneros mais produzidos entre os anos de 1994 e 2014 são documentário (39), biografia/drama (19), comédia/drama (21) e comédia (7).

Esses dados realçam a predominância de elementos dramáticos nos filmes atuais com indivíduos com deficiência, já que entre os cinco gêneros mais produzidos no período, o primeiro é o drama e o terceiro e o quarto têm características próximas a esse gênero.

Tal constatação foi verificada, também, nos estudos de Albuquerque (2008), quando focalizou a representação do indivíduo com deficiência física no cinema brasileiro contemporâneo. Na seçáo teórica, fundamentado pelos estudos de Martin F. Norden (1994) ${ }^{18}$, o autor discute sobre a representaçáo da pessoa com deficiência física no cinema mundial, dos primeiros anos de invenção aos dias atuais.

Albuquerque (2008) divide, por meio das ideias de Norden (1994), a representação da pessoa com deficiência em cinco momentos históricos diferentes.

No primeiro, datado dos anos iniciais de invenção do cinema, entre o final do século XIX e início do século XX, era comum que obras cinematográficas utilizassem os personagens com deficiência como uma forma de sátira, já que no momento em que eram produzidas, as ruas de Nova York estavam cheias de pedintes com falsas deficiências, que as utilizavam como forma de conseguir dinheiro na rua. Esses episódios foram retratados em alguns curta-metragens com um tom humorístico.

O segundo momento corresponde à produção de freakshows, estilo de filme inspirado nos antigos circos dos horrores, forma de entretenimento que perdurou até a metade do século

${ }^{18}$ NORDEN, M.F. The cinema of isolaton: a history of disability in the movies. New Jersey: Rutgers University, 1994. 
XX e trazia corpos humanos com deformaçôes físicas nos espetáculos como forma de aguçar a curiosidade, causar impacto e chocar as pessoas.

O terceiro momento retrata a pessoa com deficiência a partir da vilania, uma vez que uma das ideias recorrentes na metade do século XX era a de que, por não serem considerados normais, os indivíduos com deficiência eram revoltados e queriam se vingar das outras pessoas.

O quarto momento, correspondente às décadas posteriores à Segunda Guerra Mundial, por consequência desse fato, representava o indivíduo com deficiência como herói, já que após os combates, um número grande de soldados americanos voltou com alguma deficiência física.

O último momento citado pelo autor tem seu início entre as últimas décadas do século XX e começo do século XXI e retrata a pessoa com deficiência comumente em filmes de drama, focalizando os dramas pessoais do indivíduo/personagem.

Segundo o articulista, essas representaçóes cinematográficas são tendências que prevaleceram em alguns momentos históricos. Isso não significa que elas são estanques e não coexistem em uma mesma época.

Em nosso estudo, no qual focalizamos as diferentes deficiências, também encontramos o drama como o gênero fílmico predominantemente mais propagado nas obras contemporâneas.

No gráfico abaixo, vemos que o drama corresponde a quase $50 \%$ dos títulos encontrados no levantamento (46\%), o documentário 16\%, a biografia/drama 8\%, assim como a comédia/drama com $8 \%$ também e a comédia com $2 \%$.

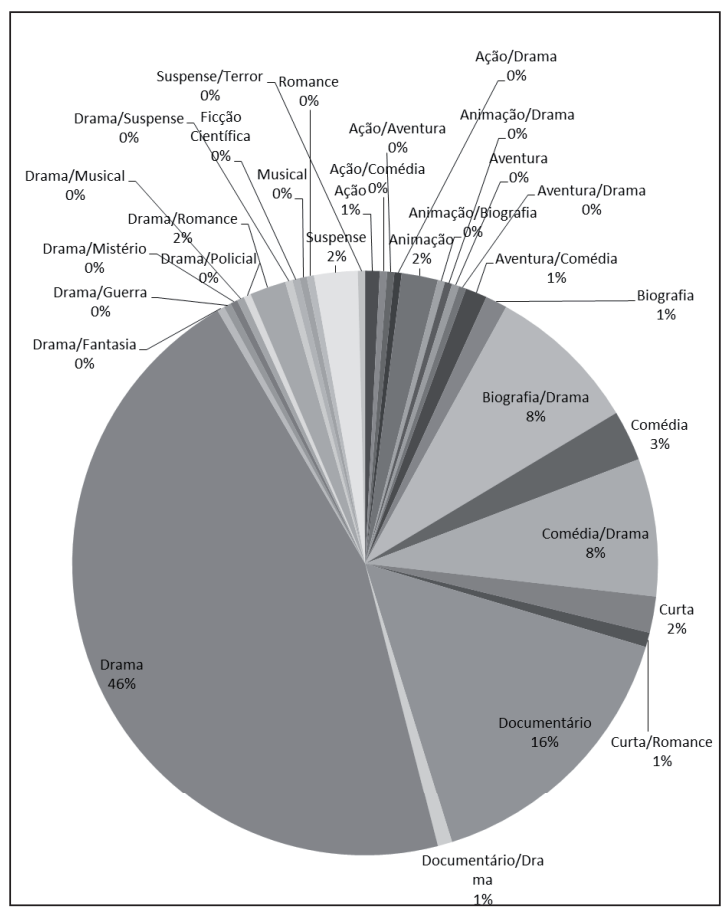

Gráfico 4 - Porcentagem de títulos por gênero fílmico Fonte: elaboração própria. 
A soma da porcentagem dos três primeiros gêneros com características dramáticas no enredo já garante $60 \%$ do total de títulos, o que indica a forte predominância do uso de elementos desse gênero para tratar da deficiência nas grandes telas.

A linguagem desse gênero geralmente é comovente para traduzir a força da resistência do personagem nos embates do mundo que o cerca.

Segundo Nogueira (2010), o drama cinematográfico tem como objeto o ser humano em situaçóes cotidianas mais ou menos complexas, com implicaçóes afetivas ou causadoras de inescapável polêmica social.

O autor aponta que, diferentemente da comédia, que sublinha as fragilidades e vícios humanos, e da tragédia, que sublinha a sua elevação e virtudes, o drama explora as consequências emocionais mais inusitadas e profundas na vivência corriqueira do sujeito.

Nogueira (2010) divide o drama em subgêneros e reconhece que é seguramente o gênero fílmico mais abrangente e muitas vezes difícil de definir.

Entre esses subgêneros, ele cita o drama social e o drama psicológico. O primeiro “coloca as personagens em confronto com uma concepção do mundo na qual elas têm dificuldade em encontrar o seu lugar e as suas referências, sendo muitas vezes vítimas de contextos que negam ou agridem os seus direitos elementares" (NOGUEIRA, 2010, p. 24). Já o drama psicológico, póe o indivíduo em confronto consigo mesmo, com os medos, as incertezas, insegurança e convicções, "espelhadas frequentemente por aqueles que o rodeiam" (NOGUEIRA, 2010, p. 24).

A constatação de que o gênero drama ocupa um grande espaço nas produçóes atuais é importante se considerarmos que o cinema tem uma relação dialógica com a realidade, ou seja, ao mesmo tempo em que retrata as ideias e concepçóes que permeiam a sociedade, ele se apresenta, também, conforme já apontado por Albuquerque (2008, p. 18), como "um meio de comunicação abrangente e um importante instrumento de visualização cultural e social”.

Os modos de compreender e representar a deficiência, a maneira que ela é significada para uma sociedade, afetam diretamente as relaçóes interpessoais com essas pessoas.

As concepçôes negativas de deficiência que interferem no processo inclusivo estão condicionadas histórica e socialmente e o cinema de massa é um desses poderosos meios de comunicação social que auxiliam na perpetuação dessas ideias.

Os dados históricos apresentados por Albuquerque (2008) permitem dizer que a segregação dos indivíduos com deficiência foi um dos fatores que auxiliou, por algum tempo, a elaboração de um imaginário social que considerava essas pessoas objetos de exposição nos freakshows e até vilóes, na época que eram representados comumente pela vilania, como no filme norte-americano $A$ Ilha do Tesouro (1950), que traz a clássica figura do pirata sem um dos olhos e uma das pernas, e no britânico 007 - Contra o Satânico Dr. No (1962), no qual o principal vilão não tem uma das mãos.

O pouco convívio em sociedade talvez tenha sido o que mais possibilitou essas noçóes, que provavelmente ainda tem seus reflexos na atualidade. 
O uso predominante do gênero drama nas obras cinematográficas atuais pode refletir a imagem que fazemos hoje da pessoa com deficiência, assim como pode colaborar para reafirmar essa representação. Se considerarmos que o aluno com deficiência se constitui a partir da internalizaçáo daquilo que vivencia nas relaçóes sociais concretas, conforme apontado por Vigotski (1989), podemos supor que a ideia dramática da deficiência, veiculada pelo cinema e reproduzida nas relações em diferentes espaços sociais, trará consequências para sua formação.

Em seus estudos, Vigotski (1989) afirma que a criança vai construir sua identidade por meio das interaçóes sociais com o grupo do qual participa. A imagem que faz de si mesma é fornecida por aqueles que estão a sua volta. Em outras palavras, as interpretaçóes feitas pelo outro vão ser internalizadas e exercem um papel fundamental na construção da representação que o aluno fará de si mesmo.

Se nas telas do cinema a pessoa com deficiência é retratada como alguém que sofre, que luta para superar algo negativo, que desperta a comoção, a repercussão na vida real condicionará as pessoas olharem para o indivíduo com deficiência como alguém menor, que sofre, digno de pena. Tal olhar dirige as relaçóes sociais e, na escola, os alunos com deficiência acabam por internalizar essas visóes.

Os últimos dados sistematizado foram os países de produção mais encontrados. Entre eles, destacam-se Estados Unidos da América (97), Brasil (27), Reino Unido (13), França (12), Canadá (10), Espanha (9) e Austrália (8).

Devido ao extenso número de países encontrados, dividimos essas variáveis em dois gráficos diferentes (Gráficos 5 e Gráfico 6).

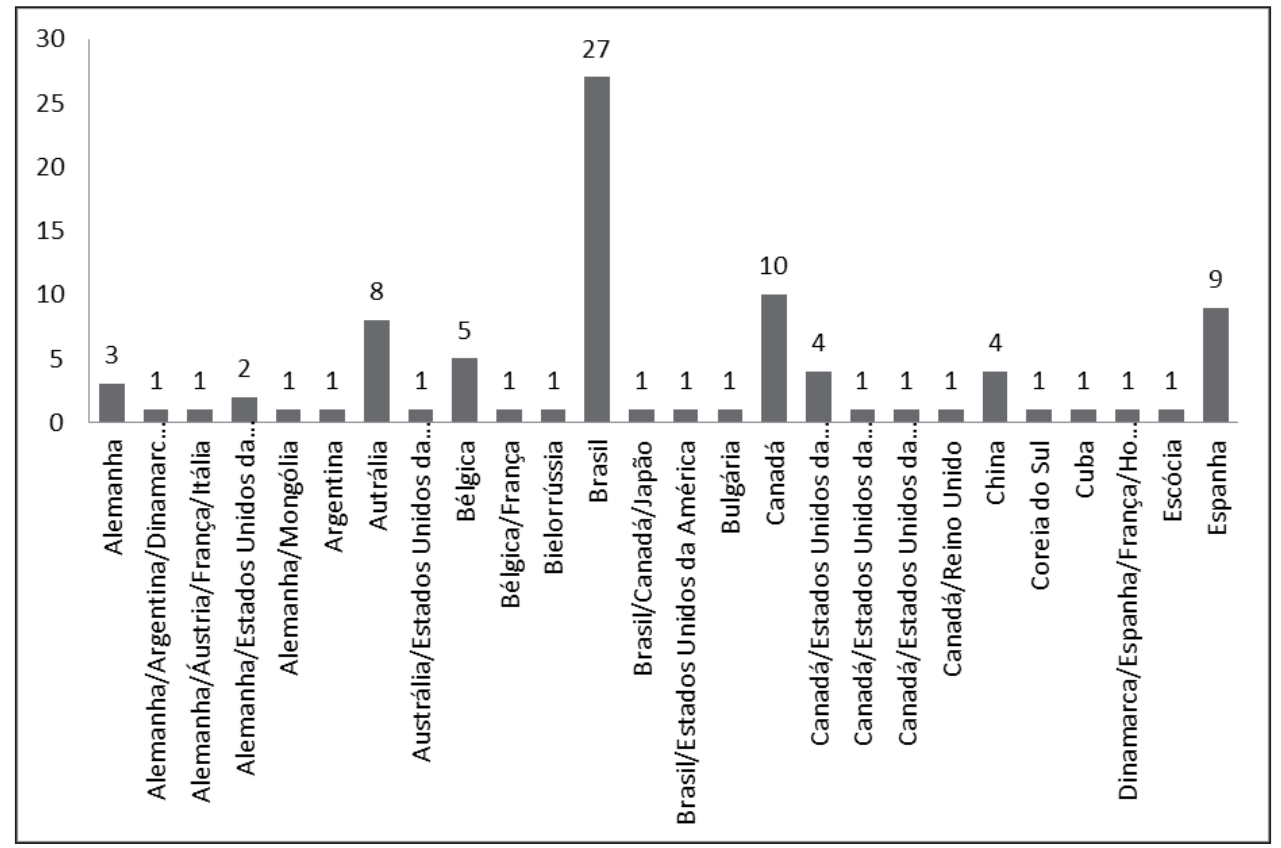

Gráfico 5 - Número de títulos por país de origem (parte 1)

Fonte: elaboração própria. 


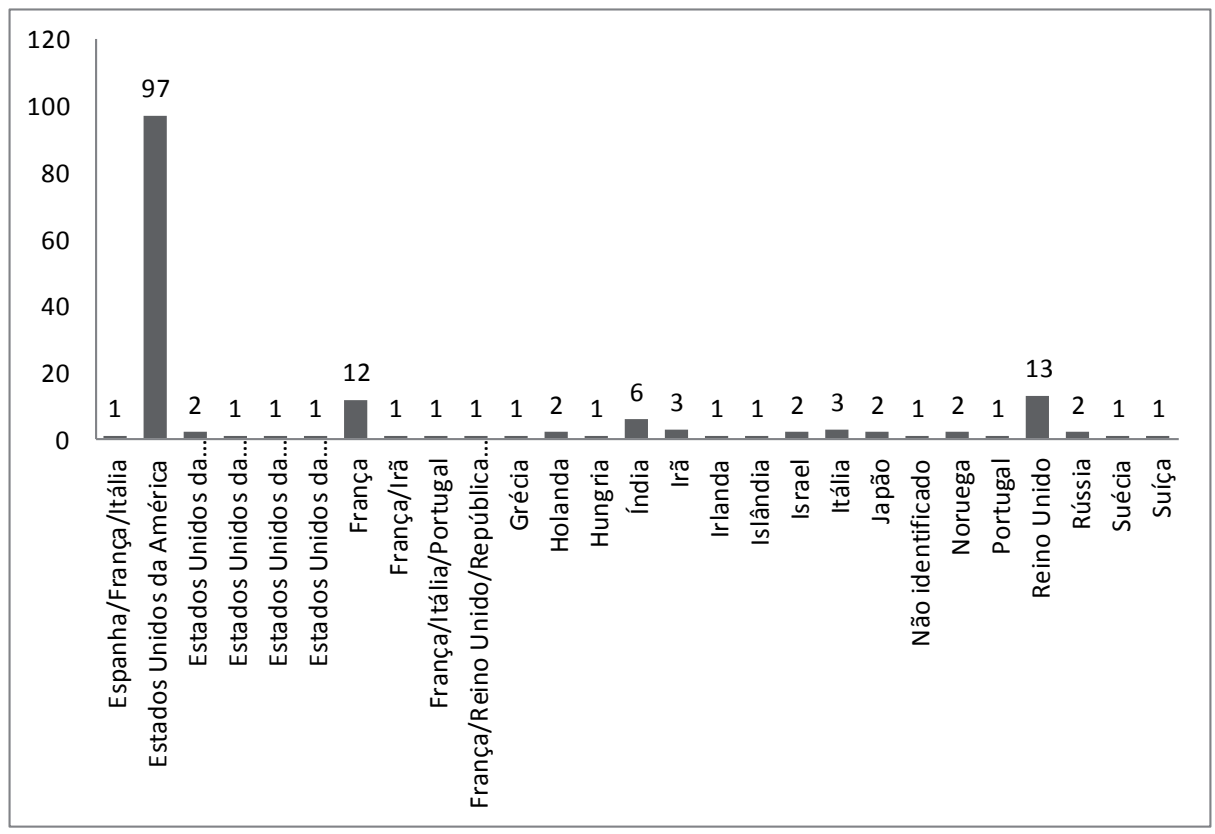

Gráfico 6 - Número de títulos por país de origem (parte 2)

Fonte: elaboração própria.

Percebemos que há um número predominante de produçóes norte-americanas sobre a temática, talvez até mesmo pelo próprio fato de a indústria cinematográfica dos Estados Unidos da América ser uma das mais consolidadas e populares no mundo e, sem dúvida, uma das maiores influenciadoras de indústrias de diferentes países.

Em texto sobre comunicação e inclusão social, Suplino (2010) discute a representaçáo social da pessoa com deficiência intelectual e do autista no cinema hollywoodiano. Ela opta por esse corpus por reconhecer a difusão da cultura cinematográfica norte-americana no mundo e a sua influência em produçóes culturais de diferentes países.

A autora analisa oito filmes produzidos nos últimos 35 anos comumente apontados em listas de obras cinematográficas sobre pessoas com deficiência intelectual e autismo: Meu filho, meu mundo (1979), Rain Man (1988), Gilbert Grape-aprendiz de sonhador (1993), Forrest Gump - o contador de histórias (1994), Código para o inferno (1998), Uma lição de amor (2001), Meu nome é Rádio (2003) e Loucos de amor (2005).

Subsidiada pela noção de identidade social proposta por Goffman $(1978)^{19}$, que defende a tese de que as concepções que sustentam as interaçóes com determinados indivíduos são estabelecidas a partir de uma identidade pré-estabelecida socialmente, Suplino (2010) observa a maneira como as interaçóes da pessoa com deficiência são exibidas nos filmes e de que modo essas representaçóes contribuem para o processo de inclusão social.

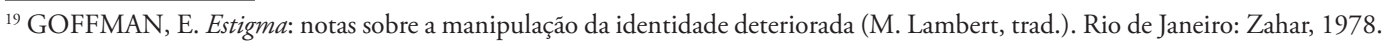


A articulista constata que normalmente as temáticas de fundo que dão suporte aos filmes são o amor, a amizade e a família. Além disso, os indivíduos com deficiência são retratados como pessoas dóceis e inocentes.

Outro ponto discutido por Suplino (2010) é o fato de essas obras pouco abordarem a questão da vida sexual dessas pessoas e do convívio social no âmbito escolar. Normalmente, como afirma a autora, são pessoas com pouca independência dentro do ambiente familiar e constituem-se como personagens reclusos; apenas em um dos casos observados o personagem e a família lutam por igualdade.

Também se observa nessas produçóes o fato de o personagem com deficiência ter sempre alguma qualidade excepcional como fator de compensação, normalmente não são retratados apenas como pessoas com algum tipo de deficiência.

[...] como se a sociedade apenas autorizasse esse personagem nas grandes telas se o mesmo tivesse algo mais que a deficiência para mostrar. [...] Dos oito filmes, apenas dois apresentam a pessoa com deficiência intelectual não possuindo esse componente excepcional. [...] Essa 'compensação' retratada nos filmes caracteriza a busca de uma 'normalização' [...] A pessoa com deficiência não pode ser apenas uma pessoa com deficiência (carga negativa); para [ser aceita, ela] deve apresentar algo mais/habilidades acima da norma (positivo), alcançando o equilíbrio em suas propensôes de participação social. (SUPLINO, 2010, p. 69-70).

Suplino (2010) conclui que os filmes ainda não conseguem representar a pessoa com deficiência como um cidadão participativo na vida social e pontua que a nossa sociedade está em constante transformação e que o papel desses sujeitos tem-se modificado, influenciado pelo movimento de inclusão.

Ela acredita que o cinema, como comunicação social, tem um papel fundamental de elemento expositivo/relator da realidade social, podendo vislumbrar até o que poder vir a ser.

Albuquerque (2008), ao analisar as obras cinematográficas Feliz Ano Velho (1987), O cego que gritava luz (1995) e Crime delicado (2005), conclui que as narrativas sobre a deficiência no cinema brasileiro contemporâneo têm muito que amadurecer e que, com o tempo, espera que surjam visóes mais positivas para um tema tão antigo.

Ambos os autores direcionam suas consideraçóes para a necessidade de representaçóes mais positivas, de modo que interfiram na realidade social e retratem as pessoas com deficiência por aquilo que essencialmente são: seres humanos com direitos e deveres.

A análise das obras cinematográficas sobre temáticas relacionadas à pessoa com deficiência permitiu identificar que as concepçóes dos professores fazem parte de um imaginário social que vem sendo retratado e reafirmado pelo cinema.

Se os docentes trazem hoje a ideia de que a deficiência é algo que depende essencialmente das condiçôes biológicas, limitante e dramática, isso é o reflexo de uma concepção construída historicamente e que teve características peculiares nos diferentes momentos e contextos sociais. E os filmes nos mostram isso. 
As obras cinematográficas sobre pessoas com deficiência podem nos ajudar na reflexão necessária para construir uma nova imagem: alguém capaz de aprender e que tem direito à educação e à participação de todos os espaços sociais.

\section{Consideraçóes FinaIS}

A inclusão dos alunos com deficiência nas escolas regulares e as concepçóes que norteiam as interações com esses indivíduos nesses espaços é um assunto complexo que ainda exige muita reflexão e prática.

Esse estudo apresenta e possibilita novas discussóes acerca da influência que as representaçóes sociais no cinema podem ter para a elaboração de ideias que comumente mediam a interação entre professores e alunos com NEE nas instituiçóes escolares inclusivas.

O olhar voltado apenas para a incapacidade, para o drama dessas pessoas, leva muitos profissionais a limitarem esses alunos, fazendo com que eles se tornem, em situaçóes educacionais, sujeitos apáticos e dependentes, o que produzirá, sem dúvida, cidadãos socialmente passivos, com pouca independência para agir nas diversas instâncias sociais e lutar por seus direitos.

As características físicas e/ou mentais não podem constituir limites para esses indivíduos, mas, sim, pontos de partida para a criação de outros caminhos que lhes permitam o acesso a toda a produção cultural da humanidade.

Considerando a importância do cinema como meio de comunicação social que reflete e influencia nossas práticas sociais, cremos que este pode ser utilizado em propostas formativas de docentes, de maneira que as obras fílmicas sejam usadas para refletir os estigmas da pessoa com deficiência e explicitar em que medida essa imagem permeia as interaçóes estabelecidas com esse indivíduo em sala de aula.

Esperamos também que o cinema, com o tempo, conforme refletem Albuquerque (2008) e Suplino (2010), traga novos olhares para as pessoas com deficiência, representando-as como indivíduos que não têm a deficiência como um drama pessoal, mas, sim, como pessoas socialmente atuantes.

\section{REFERÊNCIAS}

ALBUQUERQUE, M.A. A pessoa com deficiência e suas representaçóes no cinema brasileiro. 2008. 84f. Dissertação (Mestrado em Comunicação) - Faculdade de Comunicação Social, Universidade do Estado do Rio de Janeiro, Rio de Janeiro, 2008.

BRASIL. Declaração de Salamanca e linha de ação sobre necessidades educativas especiais. Brasília, DF: Coordenadoria Nacional para a Integração da Pessoa Portadora de Deficiência, 1994.

FERREIRA, A.M. Cinema e educação: uma reflexão sobre a formação dos educadores na/para a linguagem audiovisual. 2009. 109f. Dissertação (Mestrado em Educação) - Faculdade de Educação, Universidade Federal de Juiz de Fora, Juiz de Fora, 2009.

KATSURAGI, S. Cinema e deficiência: imagens da realidade e da arte. 2009. 72f. Trabalho de Conclusão de Curso (Licenciatura em Pedagogia) - Centro de Educação e Ciências Humanas, Universidade Federal de São Carlos, São Carlos, 2009. 
MARTIN, M. A linguagem cinematográfica. São Paulo: Brasiliense, 1990.

MONTEIRO, M.I.B.; FREITAS, A.P.; CAMARGO, E.A.A. Concepção e prática dos professores sobre deficiência: o papel do diagnóstico. In: MONTEIRO, M.I.B.; FREITAS, A. P.; CAMARGO, E. A. A. (Org.). Relaçôes de ensino da perspectiva inclusiva: alunos e professores no contexto escolar. Araraquara: Junqueira \& Marin, 2014. p.23-39.

NOGUEIRA, L. Manuais de Cinema II: Géneros Cinematográficos. Covilhã: Livros LabCom [online], 2010. Disponível em: <http://www.labcom-ifp.ubi.pt/ficheiros/nogueira-manual_II_generos_ cinematograficos.pdf >. Acesso em: 27 set. 2016.

RIZZO JUNIOR, S.A. Educação audiovisual: uma proposta para a formação de professores de Ensino Fundamental e de Ensino Médio no Brasil. 2011. 150f. Tese (Doutorado em Meios e Processos Audiovisuais) - Escola de Comunicaçóes e Artes, Universidade de São Paulo, São Paulo, 2011.

SILVEIRA, K.A.; ENUMO, S.R.F.; ROSA, E.M. Concepçóes de professores sobre inclusão escolar e interaçóes em ambiente inclusivo: uma revisão de literatura. Revista Brasileira de Educação Especial, Marília, v.18, n.4, p.695-708, 2012.

SUPLINO, I.O. Comunicação e inclusão social: análise das contribuiçôes do cinema para o processo de inclusão social. Contemporânea: Revista da Universidade Estadual do Rio de Janeiro, Rio de Janeiro, v.8, n.3, p.58-73, 2010.

VIGOTSKI, L. S. Fundamentos de defectologia. Obras completas. Playa, Ciudad de La Habana: Editorial Pueblo y Educación, 1989. v.5.

Recebido em: 30/03/2016

Reformulado em: 20/08/2016

Aprovado em: 20/10/2016 
AMARAL, M.H. \& MONTEIRO, M.I.B. 